\title{
Nutrition, immunity and the fetal and infant origins of disease hypothesis in developing countries
}

\author{
Sophie E. Moore \\ MRC Dunn Clinical Nutrition Centre, Hills Road, Cambridge CB2 2DH, UK and Keneba, The Gambia
}

There is now a substantial body of evidence to suggest that the chances of developing a number of diseases in adult life are influenced by the rate of fetal and early infant growth of the individual; the 'fetal and infant origins of adult disease' hypothesis (Barker, 1994). The majority of evidence supporting this hypothesis comes from studies in the developed nations of the world and focuses on the relationship between small size at birth and later susceptibility to chronic degenerative diseases. Within the framework of the hypothesis associations have been shown to exist for diseases such as stroke, chronic obstructive lung disease, CHD and its risk factors, hypertension, noninsulin-dependent diabetes mellitus, abnormalities in lipid metabolism and blood coagulation (Barker et al. 1991, 1993, Barker, 1996).

From a recent study in The Gambia (Moore et al. 1997), novel evidence has emerged that nutritional programming during fetal life may have permanent effects on immunocompetence. The aim of the present review is to further examine the implications that the fetal and infant origins of disease hypothesis has in developing countries and to extend the idea of disease programming beyond the chronic diseases of affluence to those involving susceptibility to infectious diseases.

\section{The developing country scenario}

\section{Excess of low birth weights}

It is estimated that there are twenty-five million babies annually born below the World Health Organization lowbirth-weight cut-off of $2.5 \mathrm{~kg}$, and that over $90 \%$ of these are in developing countries (World Health Organization, 1984). There is a variety of factors which can influence small size at birth, including certain maternal infections, short birth intervals, excessive energy expenditure after mid-pregnancy and pre-eclampsia. However, statistical analysis of these factors show that it is a poor maternal diet that is of key importance. The best way to illustrate this is to reverse the presumed nutritional deficit by supplementing women who would otherwise face diets chronically marginal in nutrients during pregnancy. Ceesay et al.
(1997) provide the most recent evidence for the effectiveness of maternal dietary supplementation in a study from the West Kiang region of The Gambia. In this 5-year prospective trial, 2287 women of childbearing age were randomized by village into control or intervention groups; the intervention group receiving a daily biscuit supplement (providing $4250 \mathrm{~kJ}(1020 \mathrm{kcal})$ and $22 \mathrm{~g}$ protein) during the second half of pregnancy. There was a highly significant positive effect of the supplement on the average birth weight, a highly significant effect on reducing the prevalence of low-birthweight infants, and on perinatal mortality.

\section{The 'thrifty phenotype'}

Approximately $65 \%$ of the population in the less-developed countries of the world live in rural areas (United Nations Department of International Economic and Social Affairs, 1989). However, there is a rapid and increasing rural-urban transition and associated changes in lifestyle. In combination with the excess of low-birth-weight infants, it is clear that the fetal and infant origins of disease hypothesis is of particular importance in developing countries, since it predicts that the worst health risks will affect people who suffered early undernutrition and progress to have adequate or excess nutritional intake in adulthood. This is the basis of the 'thrifty phenotype' concept (Hales \& Barker, 1992). The key feature of this concept is that fetal undernutrition creates a metabolic response designed for situations where nutrition is marginal and that this in-built response may then be inappropriate when faced with a transition to a nutritional excess; the consequences of which may manifest as disease.

The fetal and infant origins of disease hypothesis has been explored in a handful of studies in developing countries (Table 1). These studies, mainly based in urban areas, support both the main hypothesis and the concept of the thrifty phenotype. However, it is the infectious and parasitic diseases that predominate as causes of mortality in developing countries with deaths from the chronic diseases of affluence being of a lesser importance (Fig. 1). The possibility that nutritional programming may also affect the immune system is an area that has so far received little attention.

Abbreviations: Ig, immunoglobulin; SGA, small-for-gestational age.

Corresponding author: fax $+44(0) 1223415695$ 
Table 1. Studies in developing countries supporting the fetal and infant origins of disease hypothesis

\begin{tabular}{|c|c|c|c|}
\hline Country & Subjects & Main outcome results & Reference \\
\hline Jamaica & $\begin{array}{l}\text { Kingston } \\
610 \text { children, } 6-16 \text { years }\end{array}$ & $\begin{array}{l}\text { Biood pressure in childhood inversely related to } \\
\text { birth weight } \\
\text { Glycaemic control and serum cholesterol related to } \\
\text { short birth length }\end{array}$ & Forrester et al. (1996) \\
\hline & $\begin{array}{l}\text { Kingston } \\
77 \text { children, } 10-12 \text { years }\end{array}$ & $\begin{array}{l}\text { Poor maternal nutritional status related to higher } \\
\text { blood pressure in offspring }\end{array}$ & Godfrey et al. (1994b) \\
\hline India & $\begin{array}{l}\text { Pune } \\
379 \text { children, } 4 \text { years } \\
\text { Mysore, South India } \\
517 \text { adults, } 38-60 \text { years }\end{array}$ & $\begin{array}{l}\text { Plasma glucose and insulin levels ( } 30 \text { min after an } \\
\text { oral glucose load) inversely related to birth weight } \\
\text { Small size at birth associated with raised } \\
\text { prevalence of CHD }\end{array}$ & $\begin{array}{l}\text { Yajnik et al. (1995) } \\
\text { Stein et al. (1996) }\end{array}$ \\
\hline The Gambia & $\begin{array}{l}\text { West Kiang } \\
675 \text { children, } 1-9 \text { years }\end{array}$ & $\begin{array}{l}\text { Blood pressure related to season of birth: } \\
<8 \text { years, highest in those born in dry season; } \\
>8 \text { years, highest in those born in wet season }\end{array}$ & Margetts et al. (1991) \\
\hline
\end{tabular}

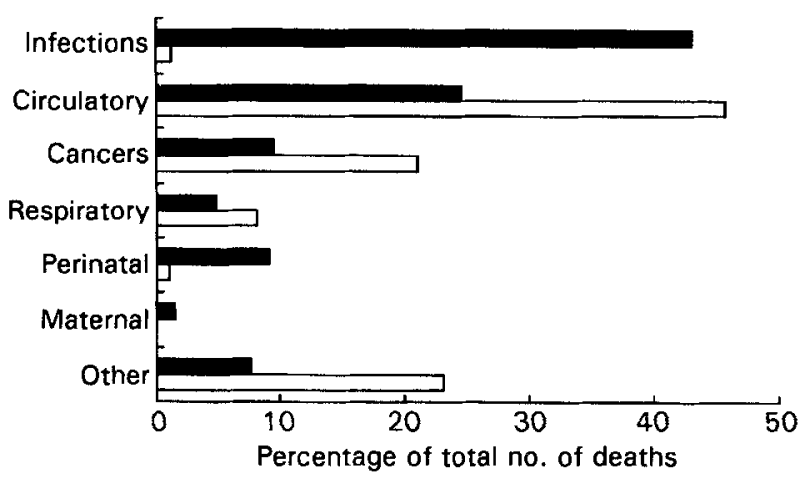

Fig. 1. Causes of death in the developed $(\square)$ and developing world, 1996. (Adapted from World Health Organization, 1997.)

\section{Nutritional programming}

In order to investigate the effects of maternal nutrition on future programming, either cross-sectional studies investigating effects between small-for-gestational age (SGA) infants and appropriate-for-gestational age infants, or cohort studies in which an entire population of pregnant women has been subjected to nutritional deprivation, such as during the Dutch Hunger Winter of 1944-45 (Stein et al. 1975), can be employed. In rural Gambia, we have had the opportunity to study a similar situation, in which the effects of an annual food shortage during a hungry season are compounded by the simultaneous need to work hard to produce the next year's crops (Cole, 1993; Prentice \& Cole, 1994). Pregnant and lactating women are not exempt from the resulting increase in energy expenditure during the hungry season and, thus, coupled with the fall in energy intake there is a depletion of maternal body fat stores (Fig. 2).

The profound seasonality in this rural area of The Gambia, and the cyclical effect of weight loss and regain (Fig. 3), has been demonstrated since documentation began in 1949 (Billewicz \& McGregor, 1981) and continues to date. As a result, there is also a profound annual hungryseason effect on birth weight (Fig. 4), with a peak-to-trough difference of approximately $200-300 \mathrm{~g}$. This model of seasonality provides us with a continuous means to explore the consequences of poor maternal diet on fetal growth and future programming.
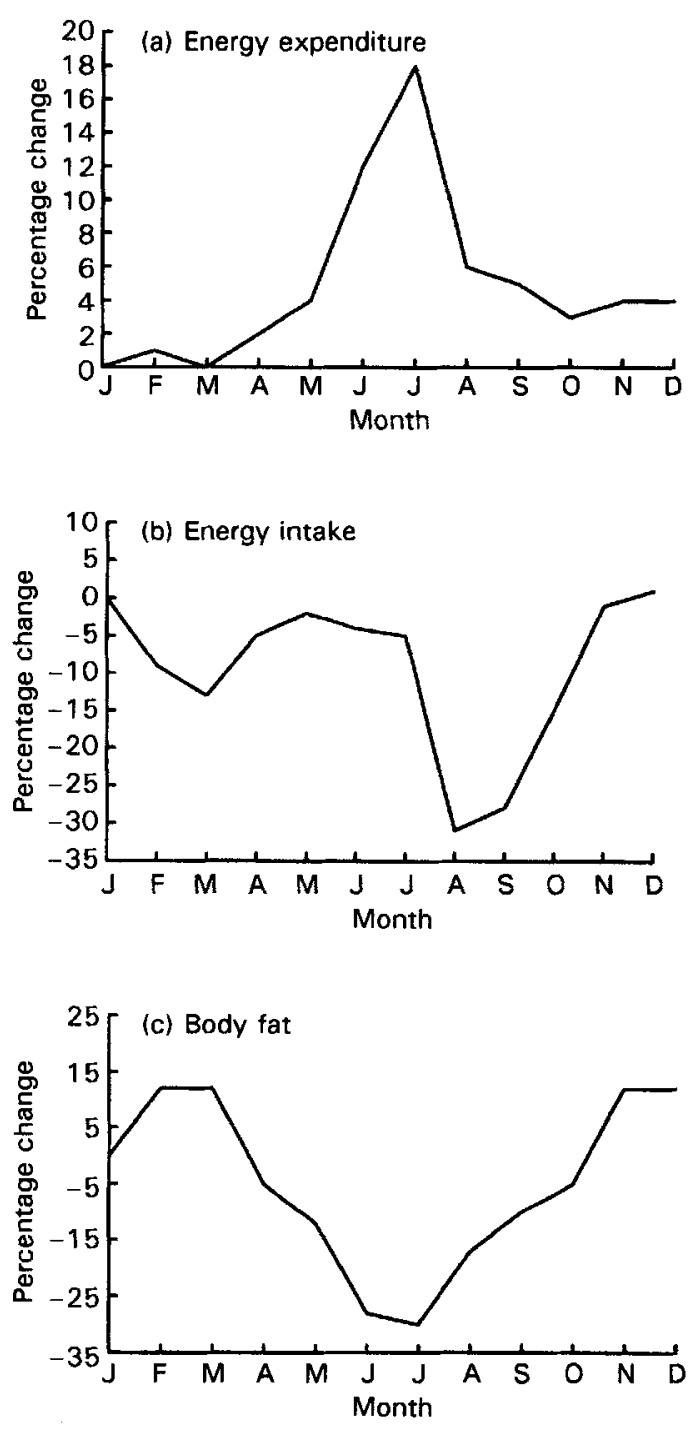

Fig. 2. Changes in (a) energy expenditure, (b) energy intake and (c) body fat stores by month of the year. (Adapted from Prentice, 1984; Prentice \& Cole, 1994.)

Since 1949, detailed records of births and deaths have been collected in the rural subsistence-farming villages of Keneba, Kantong Kunda and Manduar. This provides a 


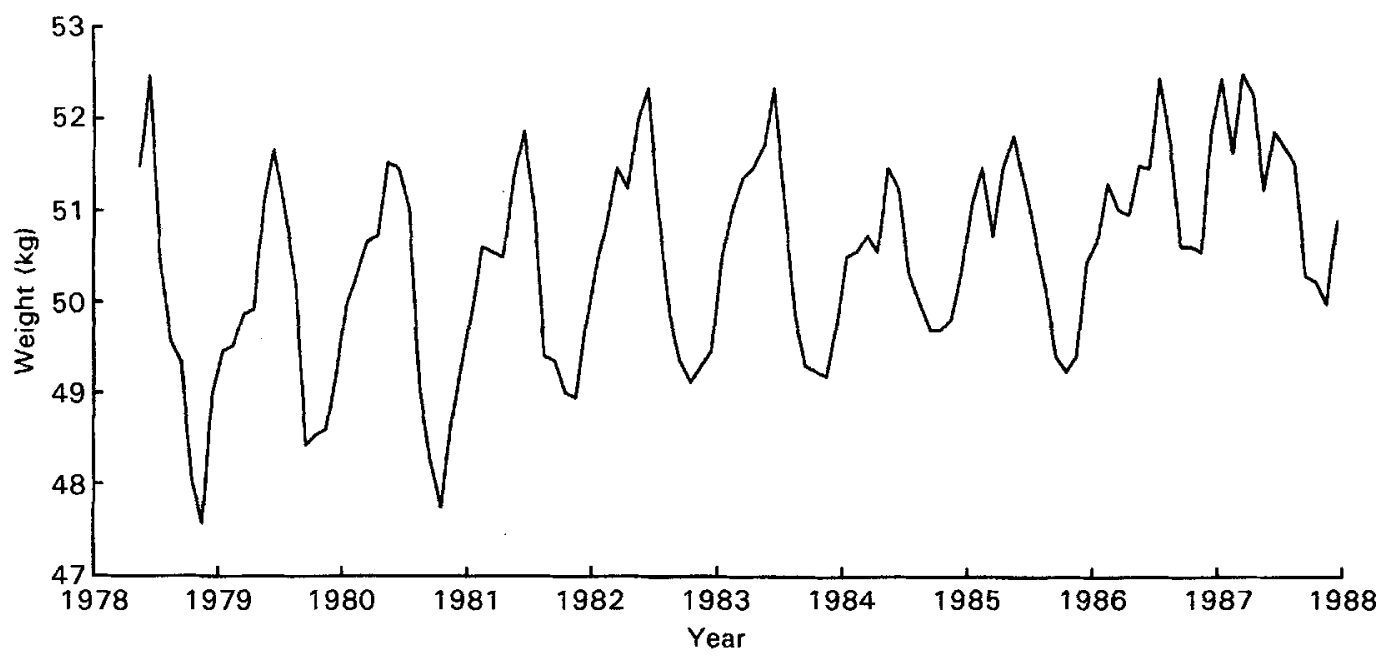

Fig. 3. Annual cycles of weight loss and regain in Gambian women. (Reproduced from Cole, 1993, with permission.)

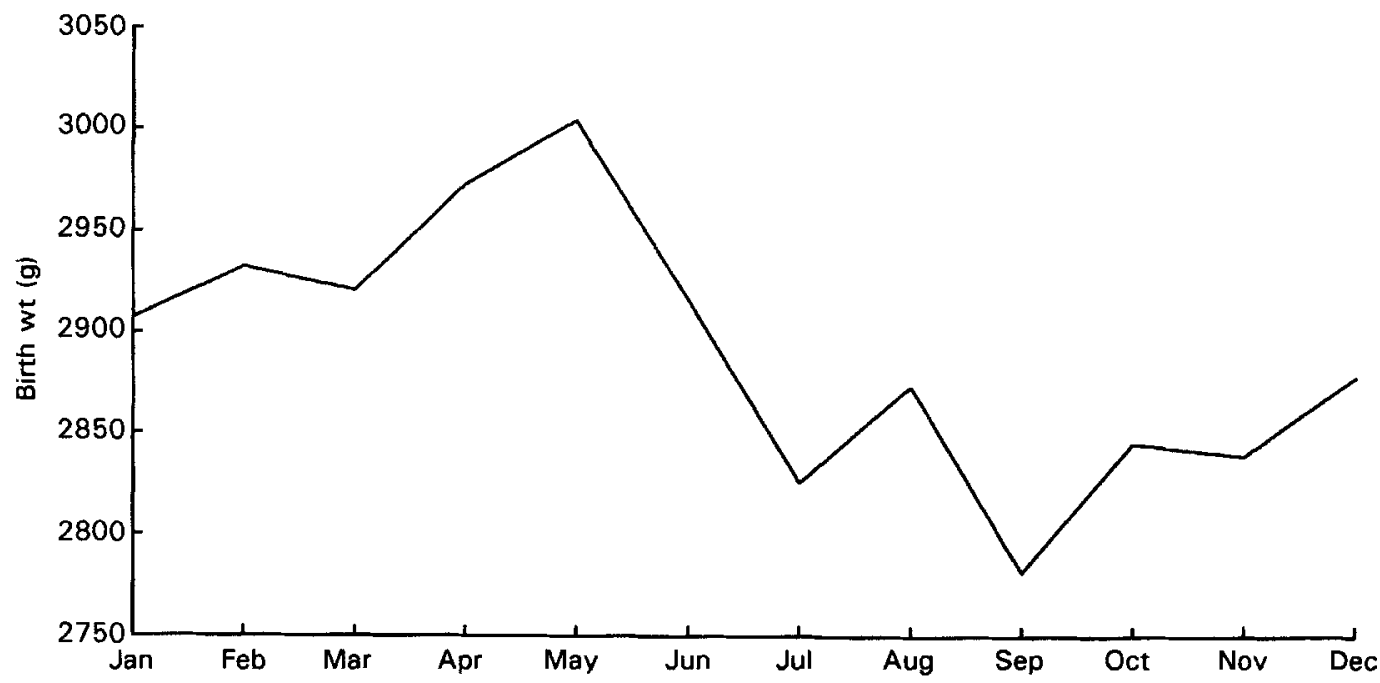

Fig. 4. Mean birth weight by month of birth. Data from women in West Kiang region of The Gambia.

dataset of 3102 individuals aged $0-45$ years with known month of birth and current fate (alive 2025, known date of death 1077). This population was used to test the hypothesis that hungry-season birth predicts future survival by acting as a proxy indicator for early-life exposure to nutritional and infectious stresses. ANOVA revealed highly significant month-of-birth effects, with highest mortality in the hungry-season births (Moore et al. 1997). Fig. 5 shows a highly significant deviation in Kaplan-Meier survival plots (see Moore et al. 1997) for people born in the harvest (January-June) and hungry (July-December) seasons. The results indicate that prenatal or early postnatal events have programmed the future health of rural Gambians in a manner that is first manifest around puberty and is amplified with increasing age. Classification of the fortyeight deaths occurring in the over 15 year olds revealed that mortality was clearly dominated by infectious and pregnancy-related deaths. None of the deaths were related to the chronic diseases of affluence.
It is possible that early infectious insults may explain these results, since it is known that exposure to early infections, particularly measles, can have a permanent effect on the immune system (Aaby et al. 1990, 1993). However, a long-term consequence of nutritional programming on the immune system seems a more likely explanation for this current observation.

\section{Evidence for programming of the immune system}

\section{Protein-energy malnutrition and immune function}

Immunological competence and nutritional status are two of the most important determinants of mortality and morbidity. They are not independent indices and the nature of their relationship is central to many health problems (Morgan, 1997). It is widely recognized that the immune system cannot function optimally if malnutrition is present, and the consequences that protein-energy malnutrition has 


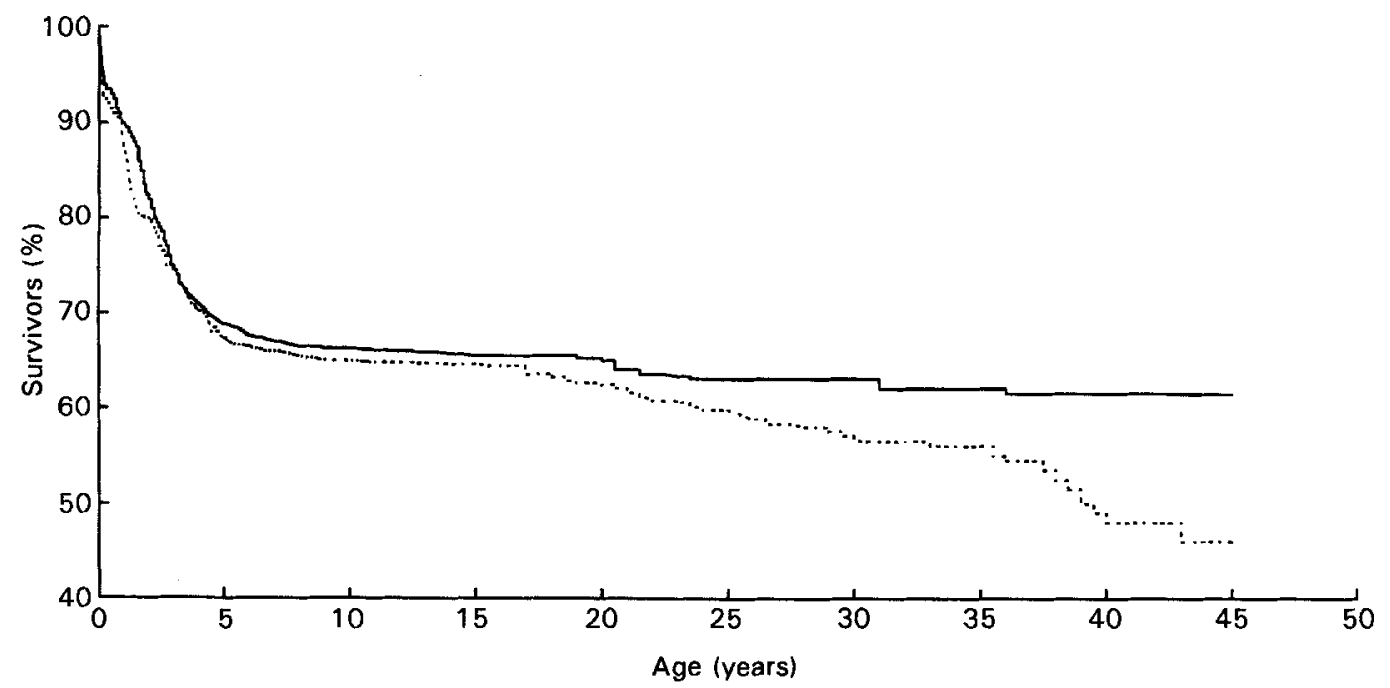

Fig. 5. Kaplan-Meier survival plots for rural Gambians divided by season of birth. (-), Harvest season; (---), hungry season. (Reproduced from Moore et al. 1997, with permission.)

on immediate immunocompetence have been extensively reviewed. Lymphoid tissues have a high rate of cell proliferation and a rapid turnover of proteins, making the immune system extremely vulnerable to the damaging effects of nutritional deficiencies (Chandra, 1993). In protein-energy malnutrition in man and laboratory animals, lymphoid tissue atrophy is a prominent feature, and can be observed through a decrease in weight and size of the thymus and a loss of lymphoid cells in the spleen and lymph nodes (Chandra, 1991a). Most of the host defence mechanisms are breached with delayed cutaneous hypersensitivity to both recall and new antigens (Chandra, 1993). In addition, there is a decrease in cell-mediated immunity seen through a reduction in mature fully-differentiated T-lymphocytes (particularly CD4+ helper cells) and a decrease in serum thymic factor (Chandra, 1993). Natural killer cell activity is significantly reduced (Chandra, 1992).

\section{Evidence for long-term programming}

Whilst studies in protein-energy malnutrition demonstrate the immediate effects of malnutrition on immune function, in the present context it is more important to examine what evidence exists to link the potential effects of nutritional programming on the immune system in the developing fetus. For over 180 years the relationship between malnutrition and thymic atrophy has been observed (Beisel, 1992) and from this grew the term 'nutritional thymectomy' to indicate the permanent involution of the thymus in response to malnutrition. This observation was actually made before it was established that the thymus had a key role to play in the immune system and the term has since virtually become forgotten.

In terms of general embryology, the ontogenetic differentiation steps in the development of the immune system are largely genetically regulated, but it is known that some environmental factors, such as nutrition and infection, can influence this process (Chandra, 1991b). Several components of the immune system mature early in fetal life (Whitelaw \& Parkin, 1988; Haeney, 1994) and, therefore, may be vulnerable to future programming as a consequence of maternal nutritional deprivation. Furthermore, it has long been recognized that abnormalities produced by intrauterine malnutrition are more severe and long lasting than those resulting from malnutrition after birth (Chandra, 1974). However, the extent to which these abnormalities persist, and the consequences they have on long-term health, is seemingly unknown.

\section{Small-for-gestational age infants}

Studies in SGA infants, specifically those showing the effects of disproportionate fetal growth, are of great importance as a potential means to explore the long-term consequence of intrauterine growth retardation. Newborn infants have suboptimal immune responses and are susceptible to infections. When growth retardation and nutritional deficiency complicate the picture, as in SGA infants, impairment of immuno-competence is more marked and longer lasting (Chandra, 1993). SGA infants show atrophy of the thymus, an impairment of cellmediated immunity and hypoimmunoglobulinaemia, specifically of immunoglobulin (Ig) G.

Godfrey et al. (1994a), in a retrospective study of a cohort of subjects born in Preston, UK, found an association between disproportionate fetal growth and a raised IgE level in adult life. Whilst seemingly paradoxical to the observations of hypoimmunoglobulinaemia in the SGA infant, it was suggested that this response was in fact mediated through a reduction in the TH-1 lymphocyte population as a result of the impaired thymic maturation during a critical period late in fetal development. This could allow for a dominant TH-2 response with the subsequent increase in the secretion of IgE. 


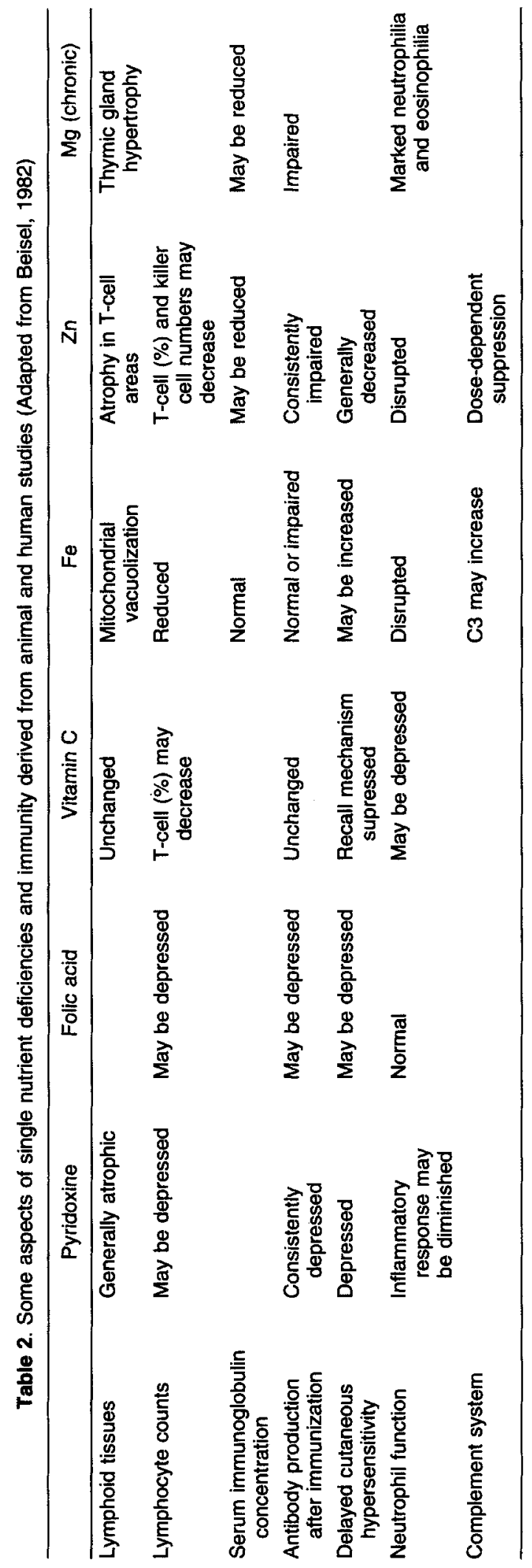




\section{Premature infants}

Premature infants face a nutritionally challenging and critical first few months of life, and their long-term immunocompetence may be disturbed as a result.

Premature infants show hypogammaglobulinaemia, with levels of IgG in cord blood decreasing in proportion to the degree of immaturity (Haeney, 1994). Infants with a very low birth weight may remain hypogammaglobulinaemic for up to 9 months of age (Haeney, 1994), but few studies have explored this further. Infants born at 28 weeks gestation have complement levels that are only $10-30 \%$ of adult values and significantly less than their full-term counterparts (Haeney, 1994). The preterm infant, therefore, is more highly compromised, since complement is an important component of opsonic activity (Hill, 1985). Neutrophil counts are significantly lower in infants of 23-27 weeks gestation as compared with the full-term infant (Whitelaw \& Parkin, 1988), but long-term studies are again absent.

In many of the studies supporting the fetal and infant origins of disease hypothesis, it is the placenta that has been implicated as having a key role to play in programming. Observations made in the premature infant, therefore, may have their limitations.

\section{The animal model}

Animal models can be manipulated to explore the immediate, longer-term and even the inter-generational effects of maternal dietary deprivation on the immune system.

Extensive work has focused on the consequence of single nutrient deficiencies on immune function and the shortterm effects that these have on the offspring are readily demonstrable (Table 2). However, even with animal models there is a definite shortage in the literature of long-term follow-up studies, particularly those focusing on more than just a single nutrient deficiency.

Importantly, animal models have been used to demonstrate that nutritional deprivation during pregnancy does not only effect the immuno-competence in the immediate offspring, but in addition an inter-generational effect can be observed in the second and third generations, even when fed on a normal control diet (Chandra, 1975; Beach et al. 1982).

\section{Conclusion}

New evidence has emerged that nutritional programming during intrauterine life may affect the development of the immune system. Although this finding has emerged in a rather unique setting which combines a natural situation with long-term demographic records, it is supported by other evidence of a strong interdependence of nutrition and immune function. The observation may be of worldwide significance to any growth-retarded fetus, and may have implications that go beyond the classic infectious diseases to cancers, auto-immune diseases, and others. Future studies will be required to replicate this finding in other populations, and to establish the precise mechanisms by which immunocompetence is impaired.

\section{References}

Aaby P, Andersen M \& Knudsen K (1993) Excess mortality after early exposure to measles. International Journal of Epidemiology 22, 156-162.

Aaby P, Bukh J, Kronborg D, Lisse IM \& da Silva MC (1990) Delayed excess mortality after exposure to measles during the first six months of life. American Journal of Epidemiology 132, 211-219.

Barker DJP (1994) Mothers, Babies and Diseases in Later Life. London: BMJ Publishing Group.

Barker DJP (1996) Growth in utero and coronary heart disease. Nutrition Reviews 54, S1-S7.

Barker DJP, Godfrey KM, Osmond C, Winter PD \& Shaheen SO (1991) Relation of birth weight and childhood respiratory infection to adult lung function and death from chronic obstructive airways disease. British Medical Journal 303, 671-675.

Barker DJP, Hales CN, Fall CHD, Osmond C, Phipps K \& Clark PM (1993) Type 2 (non-insulin-dependent) diabetes mellitus, hypertension and hyperlipidaemia (syndrome $\mathrm{X}$ ): relation to reduced fetal growth. Diabetologia 36, 62-67.

Beach RS, Gershwin ME \& Hurley LS (1982) Gestational zinc deprivation in mice: Persistence of immunodeficiency for three generations. Science 218, 469-471.

Beisel WR (1982) Single nutrients and immunity. American Journal of Clinical Nutrition 35, 417-468.

Beisel WR (1992) History of nutritional immunology: Introduction and overview. Journal of Nutrition 122, 591-596.

Billewicz WZ \& McGregor IA (1981) The demography of two West African (Gambian) villages, 1951-75. Journal of Biosocial Science 13, 219-240.

Ceesay SM, Prentice AM, Cole TJ, Foord F, Weaver LT, Poskitt EME \& Whitehead RG (1997) Maternal supplementation during pregnancy in a primary health care setting in rural Gambia: Effects on birth outcome. British Medical Journal. 315, 786-790.

Chandra RK (1974) Immunocompetence in low-birth-weight infants after intrauterine malnutrition. Lancet ii, 1393-1394.

Chandra RK (1975) Antibody formation in first and second generation offspring of nutritionally deprived rats. Science $\mathbf{1 9 0}$, 289-290.

Chandra RK (1991a) Nutrition and immunity: lessons from the past and new insights into the future. American Journal of Clinical Nutrition 53, 1087-1101.

Chandra RK (1991b) Interactions between early nutrition and the immune system. In Ciba Foundation Symposium 156; The Childhood Environment and Adult Disease, pp. 77-92 [GR Bock and $\mathbf{J}$ Whelan, editors]. Chichester: John Wiley \& Sons Ltd.

Chandra RK (1992) Protein-energy malnutrition and immunological responses. Joumal of Nutrition 122, 597-600.

Chandra RK (1993) Nutrition and the immune system. Proceedings of the Nutrition Society 52, 77-84.

Cole TJ (1993) Seasonal effects on physical growth and development. In Seasonality and Human Ecology, pp. 89-106 [SJ Ulijaszek and SS Srickland, editors]. Cambridge: Cambridge University Press.

Forrester TE, Wilks RJ, Bennett FI, Simeon D, Osmond D, Allen M, Chung P \& Scott P (1996) Fetal growth and cardiovascular risk factors in Jamaican schoolchildren. British Medical Journal 312, 156-160.

Godfrey KM, Barker DJP \& Osmond C (1994a) Disproportionate fetal growth and raised IgE concentration in adult life. Clinical and Experimental Allergy 24, 641-648.

Godfrey KM, Forrester T, Barker DJP, Jackson AA, Landman JP, Hall JStE, Cox V \& Osmond C (1994b) Maternal nutritional 
status in pregnancy and blood pressure in childhood. British Journal of Obstetrics and Gynaecology 101, 398-403.

Haeney M (1994) Infection determinants at extremes of age. Journal of Antimicrobial Chemotherapy 34, Suppl. A, 1-9.

Hales CN \& Barker DJP (1992) Type 2 (non-insulin-dependent) diabetes mellitus: the thrifty phenotype hypothesis. Diabetologia 35, 595-601.

Hill HR (1985) Host defences in the neonate: prospects for enhancement. Seminars in Perinatology 9, 2-11.

Margetts BM, Rowland MGM, Foord FA, Cruddas AM, Cole TJ \& Barker DJP (1991) The relation of maternal weight to the blood pressures of Gambian children. International Journal of Epidemiology 20, 938-943.

Moore SE, Cole TJ, Poskitt EME, Sonko BJ, Whitehead RG, McGregor IA \& Prentice AM (1997) Season of birth predicts mortality in rural Gambia. Nature 338, 434.

Morgan G (1997) What, if any, is the effect of malnutrition on immunological competence? Lancet 349, 1693-1695.

Prentice AM (1984) Adaptations to long-term low energy intake. In Current Topics in Nutrition and Disease. vol. 2, Energy Intake and Activity, pp. 3-31 [E Pollitt and P Amante, editors]. New York: Alan R. Liss Inc.
Prentice AM \& Cole TJ (1994) Seasonal changes in growth and energy status in the Third World. Proceedings of the Nutrition Society 53, 509-519.

Stein CE, Fall CHD, Kumaran K, Osmond C, Cox V \& Barker DJP (1996) Fetal growth and coronary heart disease in South India. Lancet 348, 1269-1273.

Stein Z, Susser M, Saenger G \& Marolla F (1975) Famine and Human Development. The Dutch Hunger Winter of 1944-1945. New York: Oxford University Press.

United Nations Department of International Economic and Social Affairs (1989) Population Studies. no. 112, Prospects of World Urbanization 1988. New York: United Nations.

Whitelaw A \& Parkin J (1988) Development of immunity. British Medical Bulletin 44, 1037-1051.

World Health Organization (1984) The incidence of low birthweight: an update. Weekly Epidemiological Record 59, 205-212.

World Health Organization (1997) The World Health Report, 1997. Conquering Suffering: Enriching Humanity. Geneva: WHO.

Yajnik CS, Fall CHD, Vaidya U, Pandit AN, Bavdekar A, Bhat DS, Osmond C, Hales CN \& Barker DJP (1995) Fetal growth and glucose and insulin metabolism in four-year-old Indian children. Diabetic Medicine 12, 330-336. 